\title{
Menstrual cycle related differences in the proliferative responses of cultured human endometrial stromal cells to retinoic acid
}

\author{
A. D. Loughney ${ }^{1,2}$ and C. P. F. Redfern ${ }^{2 *}$ \\ Departments of ${ }^{1}$ Obstetrics and Gynaecology and ${ }^{2}$ Medicine, The Medical School, \\ University of Newcastle upon Tyne, Framlington Place, Newcastle upon Tyne NE2 4HH, UK
}

\begin{abstract}
Although ovarian-derived steroid hormones are central to the control of endometrial growth and secretory differentiation, all-trans retinoic acid, a derivative of vitamin A, may also play an important role. Since the retinoids can inhibit the proliferation of both fibroblasts and epithelial cells in experimental systems, we investigated whether the proliferation of endometrial stromal cells was inhibited by all-trans retinoic acid. A sensitive spectrophotometric assay was used to show that the proliferation rates of primary cultures of endometrial stromal fibroblasts varied with the timing of biopsy, and that all-trans retinoic acid inhibited the growth of late secretory phase cells but had no effect on cells sampled at other times. Furthermore, since the expression of mRNA encoding cellular retinoic acid binding protein type II decreases in endometrial stromal cells in the secretory phase, a rise in intracellular all-trans retinoic acid concentrations could be fundamental to the control of endometrial stromal cell proliferation and differentiation in vivo.
\end{abstract}

\section{Introduction}

During the follicular phase of the human menstrual cycle, epithelial cells from the basal stratum of endometrium proliferate to form the ducts of simple glands and a pseudostratified lining to the uterine cavity. Simultaneously, fibroblasts from the surrounding stroma proliferate, contributing to a developing functional stratum, while maintaining an intimate relationship with the endometrial glands (Tindall, 1987). The luteal phase of the menstrual cycle follows ovulation and is characterized by a reduction in cell proliferation and the secretory differentiation of endometrial epithelial tissues (Noyes et al., 1950). Although the cyclical pattern of endometrial proliferation followed by secretory differentiation occurs primarily in response to progesterone and oestradiol (Witt and Thorneycroft, 1990), other factors may also be involved.

Experimental evidence from rats has shown that derivatives of vitamin $\mathrm{A}$, the retinoids, are required for the maintenance of the differentiated phenotypes of many epithelia including endometrium; hypovitaminosis $\mathrm{A}$ leads to widespread hyperkeratinization, de novo keratinization and squamous metaplasia (Wolbach and Howe, 1925). Epidemiological data suggest that a similar underlying pathological process may occur in the epithelial tissues of humans with dietary vitamin A deficiency (Underwood, 1984). In contrast, high concentrations of retinoids promote secretory characteristics in epidermal tissues cultured from chick embryos, mice and hamsters in vitro (Fell and Mellanby, 1953; Hardy and Bellows, 1978; Covant and Hardy, 1988). Furthermore, the interaction of epithelial and stromal cells may play a vital part in controlling these changes

${ }^{*}$ Correspondence.

Manuscript received 4 May 1995. in response to the retinoids (Covant and Hardy, 1990; Hardy et al., 1990). The retinoids could also be involved in the control of human endometrial differentiation, for example promoting secretory characteristics during the luteal phase of the menstrual cycle.

Endometrial stromal fibroblasts (stromal cells) which have been established and passaged in culture express mRNA for cellular retinol binding protein type I (CRBP I) and cellular retinoic acid binding protein type II (CRABP II; Siddiqui et al., 1994) which bind retinol and its derivative all-trans retinoic acid, respectively, within the cytoplasm. In addition, these cells express mRNA for nuclear retinoic acid receptors (RARs) and retinoid-X receptors (RXRs; Prentice et al., 1992; Siddiqui et al. 1994), which are retinoic acid dependent transcriptional regulators. These findings suggest that the endometrial stroma is a target tissue for the retinoids. Recent data have shown that, in vivo, endometrial stromal cells express mRNA encoding CRBP I at a constant level but that the expression of mRNA encoding CRABP II varies, being highest in the follicular phase and then falling during the luteal phase of the menstrual cycle (Loughney et al., 1995). These binding proteins may modulate the intracellular concentrations of all-trans retinoic acid by altering its relative rates of synthesis and catabolism (Blomhoff et al., 1990; Napoli, 1993), so that endometrial cells may become more sensitive to all-trans retinoic acid as a result of decreased metabolism. Thus all-trans retinoic acid could be involved in bringing about the transition of human endometrium from a proliferative to a secretory phenotype.

All-trans retinoic acid can reduce the rate of cell proliferation in a dose-dependent manner in a variety of tissues. For example in vitro, all-trans retinoic acid inhibits the growth of fibroblasts derived from lung tissue (Stanulis-Praeger et al., 1986) and foreskin (Lacroix et al., 1980), and malignant epithelial cell lines 
derived from the respiratory tract (Lotan et al., 1987), large intestine (Keri et al., 1988) and breast (Lotan, 1979). Therefore, regulated increases in the intracellular concentration of all-trans retinoic acid may be partly responsible for the observed reduction in the proliferation rate of stromal cells which is a feature of the secretory differentiation of human endometrium following ovulation (Tindall, 1987). In the present study a sensitive spectrophotometric assay was used to measure the rate of proliferation of primary cultures of endometrial stromal cells sampled throughout the menstrual cycle. Using these data as a baseline, we investigated whether the effects of all-trans retinoic acid on stromal cell proliferation differ at each phase of the menstrual cycle.

\section{Materials and Methods}

\section{Preparation of stromal fibroblasts}

Endometrium was obtained by use of a Pipelle (Cornier, 1984; Eurosurgical, Nottingham) from 88 women undergoing laparoscopic surgery, including 58 undergoing sterilization and 30 with a history of pelvic pain. In each case the laparoscopic findings were normal. Subjects gave a normal menstrual history with regular menses every 28-30 days and no subjective complaint of heavy bleeding. The phase of the menstrual cycle was calculated from the date of commencement of the last menstrual period, supported by a measurement of serum progesterone. None of the subjects had used either an intrauterine coil or a hormonal method of contraception for at least three months before the study. Fully informed consent was obtained from patients before the study as required by the Newcastle Health Authority/University of Newcastle upon Tyne Joint Ethical Committee.

Stromal cells were prepared by the method of Matthews et al. (1992). Briefly, under sterile conditions, each sample was minced and then suspended in $10 \mathrm{ml}$ Hank's Balanced Salt Solution (HBSS) supplemented with $20 \mathrm{mmol}$ Hepes $1^{-1}, 2 \%$ $(\mathrm{v} / \mathrm{v})$ ultroser-G (Gibco, Paisley, UK) and $1 \mathrm{mg}$ collagenase IA $\mathrm{ml}^{-1}$ (Sigma, Poole). After agitation for $90 \mathrm{~min}$ at $37^{\circ} \mathrm{C}$, the material was passed sequentially through $45 \mu \mathrm{m}$ and $10 \mu \mathrm{m}$ nylon sieves. The resulting filtrate was centrifuged through $60 \%(\mathrm{v} / \mathrm{v})$ Percoll (Pharmacia, Milton Keynes) at $400 \mathrm{~g}$ for $15 \mathrm{~min}$ and the buffy layer was then retrieved. The yield, after Trypan blue exclusion, was between $8.0 \times 10^{6}$ and $67.0 \times 10^{\circ}$ viable cells.

\section{Proliferation assay}

Quantification of the number of cells in stromal cultures was achieved using a modification of a spectrophotometric assay described by Kueng et al. (1989). Initially, cell suspensions from each of 58 endometrial samples were split into three aliquots. Cell proliferation was measured by adjusting the concentration in the first aliquot to $2 \times 10^{5}$ viable cells $\mathrm{ml}^{-1}$ with endometrial culture medium (ECM), consisting of a 1:1 mixture of calcium-, magnesium- and phenol red-free Ham's F12 and Dulbecco's Modified Eagle's Medium (DMEM) supplemented with $20 \mathrm{mmol}$ Hepes $\mathrm{l}^{-1}, 1 \%$ (v/v) non-essential amino acids, $2 \%(\mathrm{v} / \mathrm{v})$ ultroser-G and $10 \mu \mathrm{g}$ insulin $\mathrm{ml}^{-1}$ (Sigma). Concen- trations of progesterone and oestradiol were assayed before use and found to be $64 \mathrm{nmol} \mathrm{I}^{-1}$ and $1840 \mathrm{pmol} \mathrm{l}^{-1}$, respectively; although these represent concentrations equivalent to mid-luteal serum values, no attempt was made to adjust the steroid hormone content of the ECM according to the timing of biopsy, as this would have increased the number of variables in the experimental conditions.

Aliquots of $200 \mu \mathrm{l}$ (equivalent to 40000 cells) were added to each of 44 wells of a flat-bottomed 96-well plate (Costar, High Wycombe, UK) and the cultures were incubated in a humidified atmosphere of $5 \% \mathrm{CO}_{2}$ in air at $37^{\circ} \mathrm{C}$. On each of the following 11 days, four wells were fixed with $20 \mu \mathrm{l}$ per well $11 \%(\mathrm{v} / \mathrm{v})$ glutaraldehyde in PBS under sterile conditions; the remaining cells were fed at intervals of $48 \mathrm{~h}$. On day 11, the cell nuclei were stained with $100 \mu \mathrm{l}$ per well $0.1 \%(\mathrm{w} / \mathrm{v})$ crystal violet (Gibco) in PBS at pH 7.0. After washing the cells with HBSS, the dye was solubilized with $100 \mu 110 \%$ acetic acid per well and the absorbance at $594 \mathrm{~nm}$ was recorded for each well using a plate reader.

To construct standard curves relating number of cells to absorbance, the concentration in the second aliquot was adjusted to $3.5 \times 10^{5}$ viable cells $\mathrm{ml}^{-1}$ with ECM, and $200 \mu \mathrm{l}$ (70000 cells) was added to each of four wells of a 96-well plate. Serial dilutions were then made to achieve quadruplicate suspensions down to 20000 cells per well in steps of 5000 . Culture plates were incubated for $18 \mathrm{~h}$ and the cells were then fixed with glutaraldehyde and stained with crystal violet, and the absorbances were read using a plate reader, as above.

For 40 of the stromal cell samples, the effect of all-trans retinoic acid on cell growth was measured. These included 10 samples from each of the early proliferative (days 1-7), late proliferative (days 8-14), early secretory (days 15-21) and late secretory (days 22-28) phases of the menstrual cycle. Proliferation assays were performed in the manner described using the third aliquot of cells, but ECM was supplemented with $10^{-7}$ mol all-trans retinoic acid $1^{-1}$ after the first $24 \mathrm{~h}$ in culture, and the cells were maintained in the dark.

\section{Immunofluorescent staining}

The degree of contamination of stromal cell cultures with epithelial cells before and after the culture period was determined by immunofluorescent staining. Stromal cells $\left(1 \times 10^{6}\right)$ from each of five proliferative and five secretory endometrial samples were plated in quadruplicate on sterile glass coverslips of $18 \mathrm{~mm}$ diameter in 24-well tissue culture plates (Costar) and maintained in ECM. On day 1 ( $18 \mathrm{~h}$ ) and day 11 , duplicate coverslips were retrieved and the cells were fixed with $100 \%$ methanol. Primary murine monoclonal antibody was then applied for $30 \mathrm{~min}$ at room temperature to detect either epithelial intermediate filament cytokeratins (LP34), or prolyl4-hydroxylase, a fibroblastic enzyme that is involved in the production of collagen (Konttinen et al., 1989; both from DAKO, High Wycombe). After washing the coverslips with PBS, fluorescine-conjugated sheep anti-mouse IgG was added (Boehringer Mannheim, Lewes) together with $5 \mu \mathrm{g}$ propidium iodide $\mathrm{ml}^{-1}$ to delineate the nuclei. The coverslips were then mounted on glass slides with aqueous Uvinert Mountant $(\mathrm{BDH}$, Poole), and viewed under a fluorescent microscope. 


\section{Limiting dilution assay}

Stromal fibroblasts from a further 20 endometrial samples (five from each of the early proliferative, late proliferative, early secretory and late secretory phases) were cloned by limiting dilution assay to determine the proportion of proliferating cells biopsied during each phase. For these experiments, ECM had been conditioned for 3 days above a confluent layer of endometrial stromal cells from a passaged line of normal endometrial cells (Matthews et al., 1992), and then sieved through a $0.2 \mu \mathrm{m}$ filter before use. Concentrations of progesterone and oestradiol were assayed before use and found to be $23 \mathrm{nmol} \mathrm{I}^{-1}$ and $996 \mathrm{pmol} \mathrm{l}^{-1}$, respectively. The density of viable cells was adjusted to 1 cell $\mathrm{ml}^{-1}$ in conditioned ECM, and then in each case, $200 \mu \mathrm{l}$ was added to each well of a series of twenty 96-well plates. The cultures were viewed under a light microscope after $24 \mathrm{~h}$ to confirm the presence of single cells within some of the wells; wells with no cells or more than one cell were not used. Culture plates were incubated at $37^{\circ} \mathrm{C}$ in a humidified atmosphere with $5 \% \mathrm{CO}_{2}$ and were fed on alternate days with conditioned ECM either with (10 plates) or without (10 plates) a supplement of $10^{-7} \mathrm{~mol}$ all-trans retinoic acid $1^{-1}$. After 14 days, the cells were fixed with $40 \mu \mathrm{l} 11 \%$ $(\mathrm{v} / \mathrm{v})$ glutaraldehyde in PBS per well, stained with $0.1 \%(\mathrm{w} / \mathrm{v})$ crystal violet and viewed under a light microscope to determine the number and size of colonies formed.

\section{Statistical analyses}

To compare the doubling times of cells in proliferation assays, data were grouped according to the timing of biopsy (early proliferative, late proliferative, early secretory and late secretory). Because variances appeared to be proportional to the doubling times, the doubling times were $\log _{10}$ transformed, and analysis of variance was then used to detect differences between the groups. Differences in the uptake of immunofluorescent markers in cultures were compared by calculating values of $\chi^{2}$ from $2 \times 2$ contingency tables. In limiting dilution assays, the proportions of cells from each phase of the menstrual cycle which formed colonies were compared using $2 \times k$ contingency tables. Colony sizes were compared by analysis of variance on the assumption that colony size was a continuous variable described by a normal distribution.

\section{Results}

Proliferation of endometrial stromal cells in relation to the menstrual cycle

Standard curves for each sample confirmed that absorbance increased linearly with the number of cultured stromal cells in the range tested (Fig. 1). To calculate the rate of proliferation of cells maintained in ECM without all-trans retinoic acid, in each case the natural $\log (\ln )$ of absorbance was plotted against number of days in culture and a linear regression curve was fitted to the graph. Under these culture conditions, cells were in the exponential phase of growth during the culture period (Fig. 2), and the doubling time was estimated from (ln 2)/ gradient. The mean doubling time of cells sampled during the

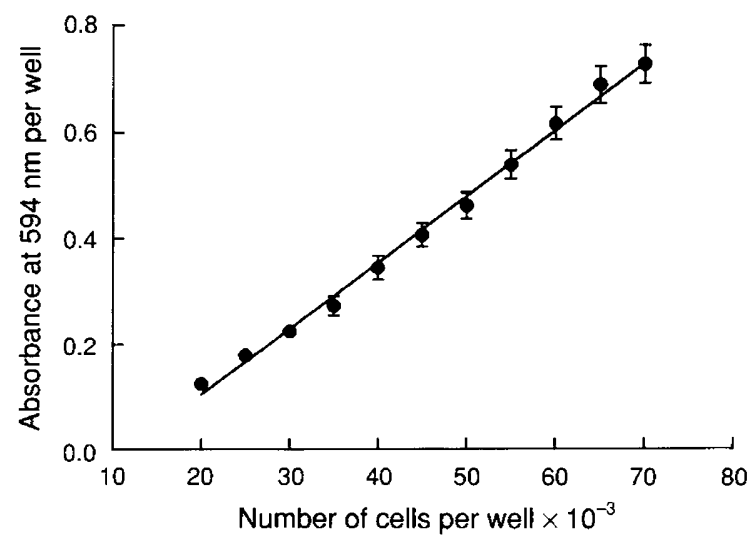

Fig. 1. Standard curve demonstrating a linear relationship between the number of human endometrial stromal cells in each well and the absorbance at $594 \mathrm{~nm}$ after staining with crystal violet $(n=58)$. Bars: $\pm 95 \%$ confidence interval.

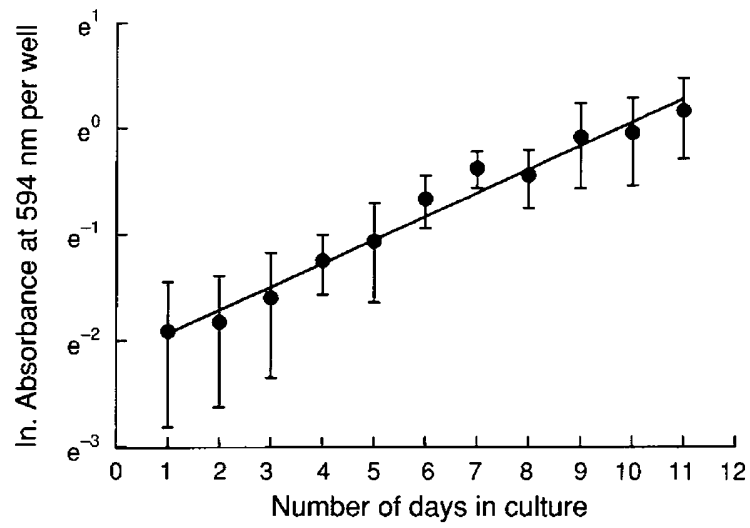

Fig. 2. Proliferation of a sample of late secretory phase human endometrial stromal cells in culture. The equation of linear regression is $y=0.22 x-2.15$ giving a doubling time of 3.15 days. Bars: $\pm 95 \%$ confidence interval.

early proliferative phase was 4.0 days ( $95 \%$ confidence interval, \pm 0.6 days), compared with $9.9 \pm 2.9$ days during the late proliferative phase, $10.0 \pm 2.7$ days during the early secretory phase and $3.9 \pm 0.4$ days during the late secretory phase (Fig. 3). Analysis of variance demonstrated a significant difference between the groups $(F=8.4 ; P<0.001)$ with a marked increase in the doubling time of cells from the early to late proliferative phases, and a decrease in doubling time from the early to late secretory phase (Tukey, $P<0.05$ ). The results also indicate that although predetermined concentrations of the steroid hormones were used in culture, the differentiated state of the stromal cells in vitro was governed by the timing of biopsy, and persisted throughout the culture period.

The mean doubling times of cells in the 40 cultures supplemented with $10^{-7} \mathrm{~mol}$ all-trans retinoic acid $1^{-1}$ were $4.5 \pm 1.3$ days during the early proliferative phase, $11.5 \pm 3.5$ days during the late proliferative phase, $11.1 \pm 3.1$ days during the early secretory phase and $10.0 \pm 2.4$ days during the late secretory phase. Paired $t$ tests were used to compare samples that were treated with all-trans retinoic acid with those that were not within each phase (Fig. 4), and demonstrated that Downloaded from Bioscientifica.com at 04/26/2023 05:27:37AM 


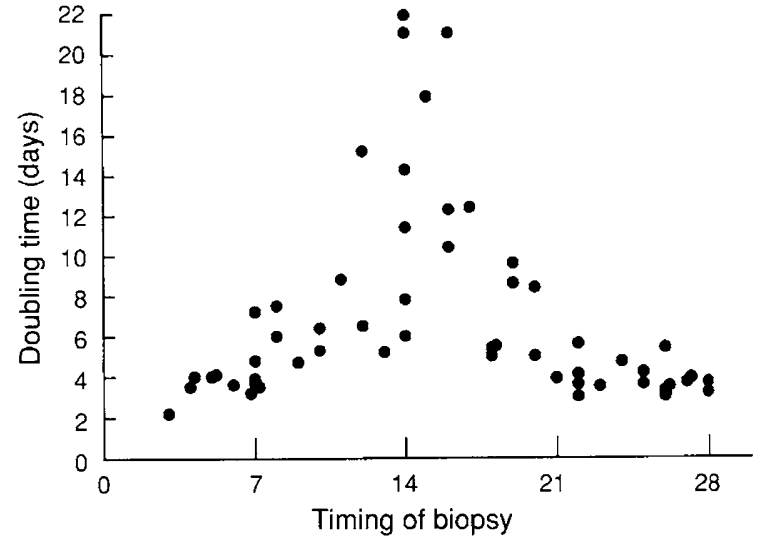

Fig. 3. Scatter plot showing the doubling times of human endometrial stromal cells in primary culture in relation to the timing of biopsy $(n=58)$.

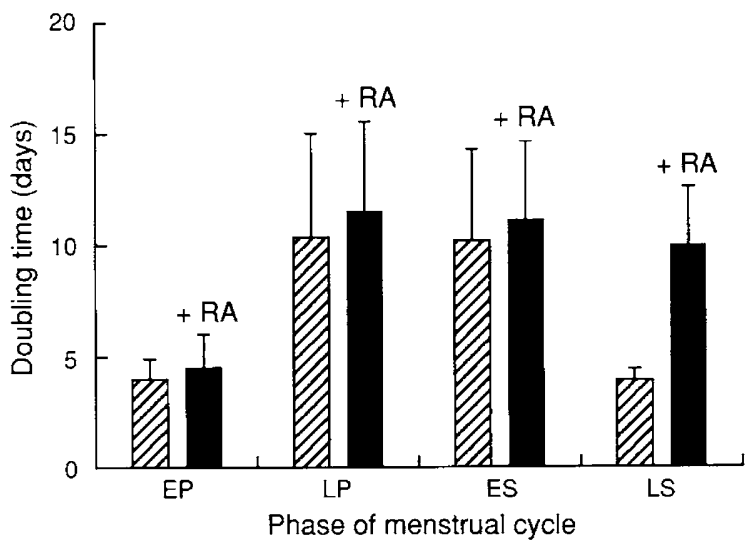

Fig. 4. Phase-specific doubling times of human endometrial stromal cells in primary culture either with $(\mathbf{\square})$ or without $(\mathbb{Z})$ all-trans retinoic acid (RA) $(n=40)$. Bars: $\pm 95 \%$ confidence interval.

all-trans retinoic acid had no effect on the doubling time of cells sampled during the early and late proliferative and early secretory phases of the menstrual cycle. In contrast, all-trans retinoic acid produced a significant 2.6 -fold increase in the doubling time of cells sampled from the late secretory phase of the menstrual cycle $\left(t_{9}=5.9 ; P<0.001\right)$.

\section{Morphology of stromal cells}

When the stromal cells were plated at low density, there was considerable variation in the size and morphology of cells, although most assumed a multifaceted appearance (Fig. 5a). As the density of cells increased, parallel arrays of needle-shaped cells predominated in the cultures, interspaced with occasional rounded cells (Fig. 5b). These findings concur with a report from Matthews et al. (1992). On immunofluorescent staining $18 \mathrm{~h}$ after piating the stromal cells, $95.7 \%$ of cells retained the anti-prolyl-4-hydroxylase monoclonal antibody while $3.0 \%$ retained the cytokeratin marker. After 11 days in culture, $99.6 \%$ of cells took up the fibroblastic marker, whereas uptake of the epithelial marker was not seen. This represented a significant
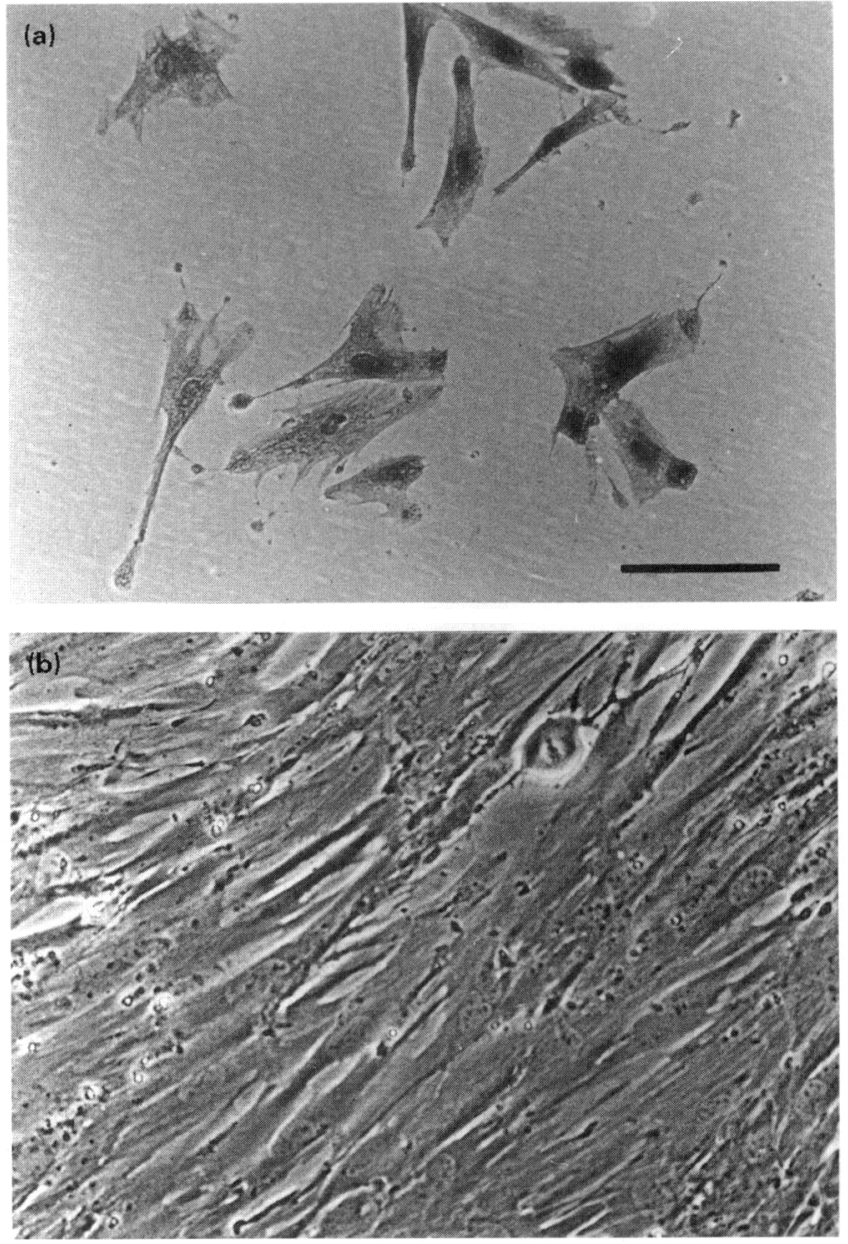

Fig. 5. Morphology of human endometrial stromal cells in primary culture: (a) multifaceted cells $24 \mathrm{~h}$ after plating at low density; (b) parallel arrays of needle-shaped cells after growth to high density. Scale bar represents $100 \mu \mathrm{m}$.

increase in the proportion of stromal cells $\left(\chi^{2}{ }_{1}=20.9\right.$, $P<0.001$ ), confirming that a high degree of purity of stromal cells had been achieved by the cell separation method used in this study, and indicated that the increased absorbance observed during the proliferation assays was due to the proliferation of stromal fibroblasts rather than epithelial or other cellular contaminants.

\section{Limiting dilution assay}

Although stromal cells frequently present a uniform morphology in vitro (Matthews et al., 1992), a heterogeneous population including stem cells, transit amplifying cells and terminally differentiated cells may be present in cultures, the proportions of each cell type varying with the timing of biopsy. Limiting dilution assays were therefore performed to determine the proportions of proliferating and quiescent stromal cells biopsied at each stage of the menstrual cycle, and the growth of established clones of cells was recorded together with their responses to all-trans retinoic acid. Twenty-four hours after plating, stromal cells were visible in 1:8 wells Downloaded from Bioscientifica.com at 04/26/2023 05:27:37AM 

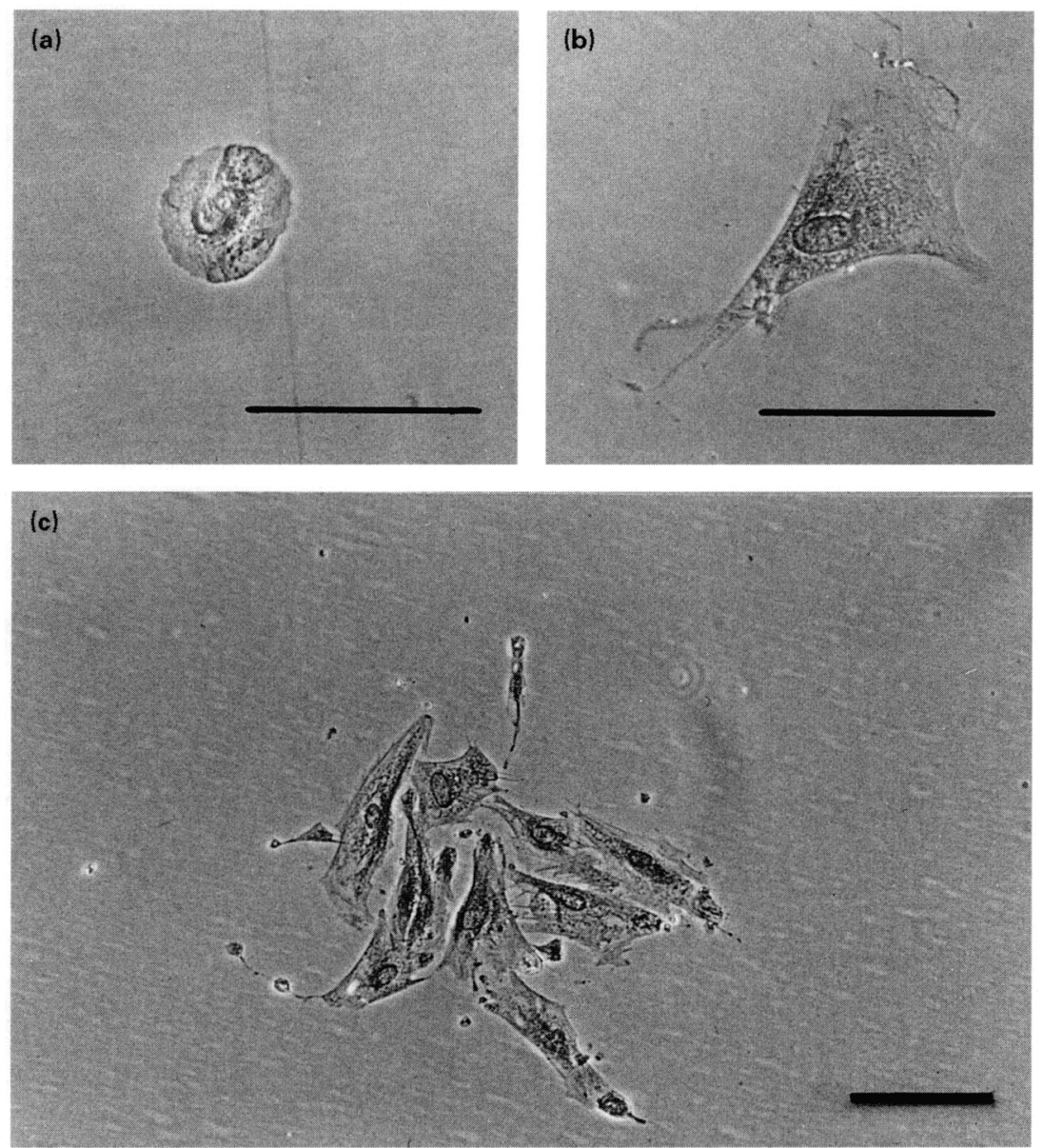

Fig. 6. Morphology of human endometrial stromal cells in limiting dilution assays: (a) 'fried egg' appearance of a stromal cell $18 \mathrm{~h}$ after plating; (b) multifaceted cell 4 days after plating; (c) clonal colony of cells retaining multifaceted appearance. Scale bar represents $100 \mu \mathrm{m}$.

compared with an expected frequency of 1:5, giving a plating efficiency of $62.5 \%$, which did not vary with the timing of biopsy. Initially, all cells appeared circular with a central nucleus (Fig. 6a). The majority retained this 'fried egg' (FE) appearance for the full 2 week culture; persisting FE cells failed to form colonies of proliferating cells and may thus have represented stromal cells at the GO phase of the cell cycle. However, some FE cells assumed a multifaceted appearance during the first days in culture (Fig. 6b), and all of these proceeded to form colonies of cells (Fig. 6c). Colonies arose from $45 \%$ of cells sampled during the early proliferative phase, $27 \%$ sampled during the late proliferative phase, $30 \%$ sampled during the early secretory phase and $38 \%$ sampled during the late secretory phase, representing a significant difference in clonogenicity between the groups $\left(\chi^{2}{ }_{3}=19.6, P<0.001\right)$. The colonies initially comprised cells of various size and morphology, with a predominance of multifaceted cells. However, when the cells were allowed to grow to confluence within the wells, parallel arrays of needle-shaped cells gained prominence and the cultures appeared similar to the non-clonogenic cultures established during proliferation assays.

Addition of $10^{-7}$ mol all-trans retinoic acid $1^{-1}$ to cultures $48 \mathrm{~h}$ after plating reduced the proportion of cells forming colonies regardless of the timing of biopsy: from the early proliferative phase, $37 \%$ of cells formed colonies (in comparison with colonies arising in the absence of all-trans retinoic acid: $\chi^{2}{ }_{1}=7.2, \quad P<0.01$ ), as did $18 \%$ from the late proliferative phase $\left(\chi_{1}^{2}=15.4, P<0.001\right), 22 \%$ from the early secretory phase $\left(\chi_{1}^{2}=12.3 ; P<0.001\right)$ and $27 \%$ from the late secretory phase $\left(\chi_{1}^{2}=18.9 ; P<0.001\right)$. The mean colony size after culture for 14 days was $12.2 \pm 1.6$ cells, and was unrelated either to the timing of biopsy or to the presence of all-trans retinoic acid (analysis of variance, $F=0.80, P=0.59$, ns). Furthermore, the morphology of cells in established colonies was unaltered by the addition of all-trans retinoic acid.

\section{Discussion}

The present results show that primary cultures of stromal cells established from endometrium biopsied during the early proliferative and late secretory phases of the menstrual cycle proliferated more rapidly in vitro than did primary cultures established from the late proliferative and early secretory phases. Furthermore, unlike stromal cells from the proliferative and early secretory phases, the proliferation of late 
secretory phase cells was inhibited by exposure to $10^{-7} \mathrm{~mol}$ all-trans retinoic acid $\mathrm{I}^{-1}$. The clear increase in cell doubling times recorded for stromal cells from the late proliferative and early secretory phases of the menstrual cycle, and for cells treated with all-trans retinoic acid in the late secretory phase, may be accounted for by a reduction in cell proliferation rate, or by an increase in the rate of cell death due to apoptosis; these two mechanisms are not mutually exclusive.

While blood vessels and glands impose an ordered structure upon human endometrium, abundant stromal cells are distributed between these tissues in an apparently chaotic manner, with no clear morphological or functional distinction between neighbouring cells (Tindall, 1987). However, in common with endothelial and epithelial cells, stromal cells from the basal stratum retain the capacity to proliferate rapidly following menstruation, in order to populate the developing functional stratum. Therefore the basal stratum may contain a high proportion of rapidly dividing stromal (possibly stem) cells. Since endometrial biopsies taken during the early proliferative phase retrieve tissue predominantly from the basal stratum, the doubling times of early proliferative phase cells in primary culture may have been short, and the cells may have had a high propensity to form clones in limiting dilution assays, owing to the predominance of these rapidly dividing cells.

During the late proliferative and early secretory phases, the developing functional stratum is populated by stromal cells originating from the basal stratum. Since stromal cells in the functional stratum possess receptors for steroid hormones (Bouchard et al., 1991) and other growth regulating factors (Smith, 1994: Tabibzadeh, 1994), during the late proliferative and early secretory phases some of these cells may differentiate to form slowly dividing (possibly transit amplifying) cells. Therefore, biopsies of endometrium obtained during the late proliferative and early secretory phases may have contained a mixture of rapidly and slowly dividing cells, which could account for an increase in the mean doubling times of cultures. In addition, if clones of cells in limiting dilution assays were more likely to be formed from rapidly dividing cells than from slowly dividing cells, an increased proportion of slowly dividing cells would be linked to a decrease in clonogenicity, as was observed during the late proliferative and early secretory phases.

The fate of endometrium in the functional stratum is determined by the success or failure of fertilization. In the absence of blastocyst-derived hCG, the ovaries withdraw their hormonal support and the permeability of the endothelial vascular network increases (Johannisson et al., 1987; Peek et al., 1992). As a result, widespread oedema and tissue ischaemia occur in the functional stratum before menstruation (Johannisson et al., 1987). Simultaneously, falling concentrations of oestradiol and progesterone may promote apoptosis in endometrial cells (Otsuki et al., 1994). On histological examination, fewer mitotic cells may be found in the functional stratum during the late secretory phase (Tindall, 1987), implying that slowly dividing cells committed to undergo terminal differentiation or apoptosis may have done so by this time. Since proliferation assays measure the mean doubling times of dividing cells, the persistence of some rapidly dividing cells would result in a decrease in the observed doubling time in samples from the late secretory phase. Furthermore, as a result of apoptosis, rapidly dividing cells may have formed a high proportion of the viable stromal cells biopsied during the late secretory phase, thereby accounting for an increase in clonogenicity.

In vivo, proliferative phase stromal cells express high levels of mRNA encoding CRABP II (Loughney et al., 1995), which may promote the metabolism of all-trans retinoic acid to inactive polar metabolites (Blomhoff et al., 1990; Napoli, 1993). If the expression of mRNA encoding CRABP in vivo is reflected in primary cultures in vitro, this binding protein could diminish the potency of all-trans retinoic acid in stromal cells sampled during the proliferative phase. Conversely, the expression of mRNA encoding CRABP II in secretory phase tissue is greatly reduced in vivo (Loughney et al, 1995); these cells may therefore be more sensitive to all-trans retinoic acid in primary cuiture, as has been shown for cells sampled during the late secretory phase.

Although the proliferation rate of cells in primary culture varied with the timing of biopsy and the presence of all-trans retinoic acid, these factors bore no relationship to mean colony size in limiting dilution assays. However, small differences in colony sizes may not have been detectable under the present experimental conditions. Alternatively, it is possible that, in vitro, all-trans retinoic acid inhibits the growth of cells sampled during the late secretory phase by an indirect mode of action, perhaps by blocking the production of autocrine growth factors by cultured cells. Since cells in limiting dilution assays were fed with conditioned ECM, such growth factors may have been present despite the subsequent addition of all-trans retinoic acid.

The fact that clonogenicity was reduced by all-trans retinoic acid in cells sampled throughout the menstrual cycle, whereas doubling time was affected only in the late secretory phase cells, implies that all-trans retinoic acid may have had two distinct effects on stromal cells: (1) inducing quiescence of cells independent of the phase of the menstrual cycle, and (2) reducing cell growth in vitro in the late secretory phase by inducing apoptosis or delaying progression through the cell cycle. Whether these two effects could be driven by the same molecular mechanism is unknown, but the coincidence between reduced expression of mRNA encoding CRABP II (Loughney et al., 1995) and the inhibition of cell proliferation by all-trans retinoic acid suggests that two distinct mechanisms may be involved.

In conclusion, all-trans retinoic acid may promote the secretory differentiation of the endometrial epithelium by a mechanism involving the mediation of stromal cells, but it may also participate in the preparation of the stromal cells for menstruation if fertilization does not occur. These possibilities are not mutually exclusive and will be addressed in further work investigating the mechanisms of growth control in human endometrial stromal cells during the menstrual cycle.

A. D. Loughney is the recipient of a Training Fellowship from Action Research. The authors acknowledge gratefully the assistance of W. Dunlop, Department of Obstetrics and Gynaecology, and C. J. Matthews, Department of Physiological Sciences, University of Newcastle upon Tyne, UK.

Downloaded from Bioscientifica.com at 04/26/2023 05:27:37AM 


\section{References}

Blomhoff R, Green MH, Berg T and Norum KR (1990) Transport and storage of vitamin A Science 250 399-404

Bouchard P, Marraoui J, Massai MR, Medalie DA, deZiegler D, Perrot-Applanat M, Frydman R and Bergeron C (1991) Immunocytochemical localization of oestradiol and progesterone receptors in human endometrium: a tool to assess endometrial maturation Baillières Clinical Obstetrics and Gynaecology $\mathbf{5}$ $107-115$

Cornier E (1984) The pipelle: a disposable device for endometrial biopsy American Journal of Obstetrics and Gynecology 148 109-111

Covant HA and Hardy MH (1988) Stability of the glandular morphogenesis produced by the retinoids in the newborn hamster cheek pouch in vitro Journal of Experimental Zoology 246 139-149

Covant HA and Hardy MH (1990) Excess retinoid acts through the stroma to produce mucous glands from newborn hamster cheek pouch in vitro Journal of Experimental Zoology 253 271-279

Fell HB and Mellanby E (1953) Metaplasia produced in cultures of chick endoderm produced by high vitamin A Journal of Physiology 119 470-488

Hardy MH and Bellows CG (1978) The stability of vitamin A-induced metaplasia of mouse vibrossa follicles in vitro Journal of Investigative Dermatology $71236-241$

Hardy MH, Dhouailly D, Torma H and Vahlquist A (1990) Either chick embryo dermis or retinoid treated mouse dermis can initiate glandular morpho. genesis from mammalian epidermal tissue Journal of Experimental Zoology 256 279-289

Johannisson E, Landgren BM, Rohr HP and Diczfalusy E (1987) Endometrial morphology and peripheral hormone levels in women with regular menses Fertility and Sterility 48 401-408

Keri G, Balogh A, Teplan I and Csuka O (1988) Comparison of the tyrosine kinase activity with the proliferation rate in human colon solid tumors and tumor cell lines Tumor Biology 9 315-322

Konttinen YT, Nykänen P, Nordström D, Saari H, Sandelin J and Santavirda J (1989) DNA synthesis in prolyl-4-hydroxylase positive fibroblasts in situ. An autoradiography-immunoperoxidase double labelling study Journal of Rheumatology 16 339-345

Kueng W, Silber E and Eppenberger U (1989) Quantification of cells cultured on 96-well plates Analytical Biochemistry 182 16-19

Lacroix A, Anderson GDL and Lippman ME (1980) Retinoids and cultured human fibroblasts. Effects on cell growth and presence of cellular retinoic acid binding protein Experimental Cell Research 130 339-344

Lotan R (1979) Different susceptibilities of human melanoma and breast carcinoma cell lines to retinoic acid-induced growth inhibition Cancer Research 39 1014-1019
Lotan R, Sacks PG, Lotan D and Hong WK (1987) Differential effects of retinoic acid on the in vitro growth and cell surface glycoconjugates of two human head and neck squamous-cell carcinomas International Journal of Cancer $\mathbf{4 0}$ 224-229

Loughney AD, Kumarendran MK, Thomas EJ and Redfern CPF (1995) Variation in the expression of cellular retinoid binding proteins in human endometrium throughout the menstrual cycle Human Reproduction 10 1297-1304

Matthews CJ, Redfern CPF, Hirst BH and Thomas EJ (1992) Characterisation of human purified epithelial and stromal cells from endometrium and endometriosis in tissue culture Fertility and Sterility 57 990-997

Napoli J (1993) Biosynthesis and metabolism of retinoic acid: roles of CRBP and CRABP in retinoic acid homeostasis Journal of Nutrition $123362-366$

Noyes RW, Hertig AT and Rook J (1950) Dating the endometrial biopsy Fertility and Sterility $13-25$

Otsuki Y, Misaki O, Sugimoto O, Ito Y, Tsujimoto $Y$ and Akao Y (1994) Cyclic $b c l-2$ gene expression in human uterine endometrium during the menstrual cycle Lancet $344 \quad 28-29$

Peek M, Landgren BM and Johannisson E (1992) The endometrial capillaries during the normal menstrual cycle: a morphometric study Human Reproduction 7 906-911

Prentice A, Matthews CJ, Thomas EJ and Redfern CPF (1992) The expression of retinoic acid receptors in cultured human endometrial stromal cells and effects of retinoic acid Human Reproduction 7 692-700

Siddiqui NA, Loughney AD, Thomas EJ, Dunlop W and Redfern CPF (1994) Cellular retinoid binding protein and nuclear retinoic acid receptors in endometrial epithelial cells Human Reproduction 9 1410-1416

Smith SK (1994) Growth factors in the human endometrium Human Reproduction 9 936-946

Stanulis-Praeger BM, Jacobus CH and Nuttall AE (1986) Hydrocortisone modulates RA-induced growth inhibition of normal and transformed human embryonic lung fibroblasts Nutrition in Cancer 8 171-184

Tabibzadeh S (1994) Cytokines and the hypothalamic-pituitary-ovarianendometrial axis Human Reproduction 9 947-967

Tindall VR (1987) Menstruation and other cyclical phenomena. In Jeffcoate's Principles of Gynaecology pp 72-79 Ed. VR Tindall. Butterworth, London

Underwood BA (1984) Vitamin $A$ in animal and human nutrition. In The Retinoids, Volume 1 pp 281-392 Ed. MB Sporn, AB Roberts and DS Goodman. Academic Press, New York

Witt BR and Thorneycroft IH (1990) Reproductive steroid hormones: generation, degradation, reception and action Clinics in Obstetrics and Gynecology 33 563-575

Wolbach SB and Howe PR (1925) Tissue changes following deprivation of fat-soluble vitamin A Journal of Experimental Medicine 43 753-777 